\title{
DAERAH PENANGKAPAN IKAN TUNA (Thunnus sp.) DI SANGIHE, SULAWESI UTARA
}

\author{
(Tuna fishing ground in Sangihe, North Sulawesi)
}

\author{
Joneidi Tamarol ${ }^{1}$ dan Julius Frans Wuaten ${ }^{1}$ \\ ${ }^{1}$ Program Studi Teknologi Penangkapan Ikan, Politeknik Negeri Nusa Utara, Sulawesi Utara.
}

\begin{abstract}
Penelitian ini bertujuan memetakan dan menginventarisir hasil tangkapan pancing tangan di Perairan Sangihe pada sembilan lokasi penangkapan ikan. Penangkapan ikan tuna di Perairan Sangihe terutama dengan menggunakan pancing tangan (tuna handline) yang oleh nelayan lokal dinamakan latage. Sarana tangkap yang biasa digunakan adalah perahu katir tipe pelang 3-5 HP; perahu katir tipe pumpboat 150 HP; kapal tipe lambut $150 \mathrm{HP}$. Hasil tangkapan perahu pelang yaitu tuna sirip kuning 2 ekor, perahur pumpboat yaitu cakalang 100 ekor dan panitang 402 ekor; kapal lambut yaitu madidihang 102 ekpr; tuna mata besar 2 ekor. Madidihang paling tinggi tertangkap pada posisi geografis $3^{\circ} 47^{\prime} \mathrm{N}-125^{\circ} 19 \mathrm{E}$ (ponton Marcopolo 03), sedangkan cakalang paling tinggi tertangkap pada posisi geografis $33^{\circ} 39^{\prime} \mathrm{N}-125^{\circ} 12^{\prime} \mathrm{E}$ (ponton Kendahe).

Kata Kunci: tuna, penangkapan ikan, pancing tangan, latage, posisi geografis

This study aims to map and to inventory the hand fishing catches in the waters of the Sangihe at nine fishing locations. Tuna fishing in the waters of the Sangihe mainly uses handlines (tuna handline) which is called latage by local fisherman. Fishing vessels used to catch tuna were pelang tye $3+5 \mathrm{HP}$ outrigger boats, pumpboat type $150 \mathrm{HP}$ outrigger boat and lambut type $150 \mathrm{HP}$ boats. The fish catches by each boat types were 2 yellow fin tunas by the pelang boats; 100 skipjacks and 402 panitangs by the pumpboat boats; and 102 yellow fin tunas and 2 big eye tunas by lambut boats. Highest number of yellowfin tunas was caught in the geographical position of $3^{\circ} 47^{\prime} \mathrm{N}-125^{\circ} 19^{\prime} \mathrm{E}$ (Marcopolo 03 pontoon) and while the lighest number of skipjacks was caught in the geographical position of $3^{\circ} 39^{\prime} \mathrm{N}-125^{\circ} 12^{\prime} \mathrm{E}$ (Kendahe pontoon)
\end{abstract}

Keywords: tuna, fishing, handline, latage, geographicat position

\section{PENDAHULUAN}

Ikan tuna (Thunnus sp.) merupakan salah satu jenis ikan ekonomis penting di dunia dån merupakan perikanan terbesar ketiga di-Indơnesia setelah udang dan ikan dasar. Selain memiliki harga yang relatif mahal bila dibandingkan dengan harga komoditas perikanan lainnya permintaan pasar untuk komoditi ini terus meningkat terutama oleh negeri Jepang. Mahyuddin (2012), menyatakan dengan ditetapkannya komoditas tuna sebagai proyek percontohan industrialisasi perikanan tangkap memiliki alasan báhwa industrialisasi perikanan tuna sangat penting eralam penyerapan tenaga kerja dan mendukang pasokan industri domestik serta memperkuat pasar internasional.

Industri perikanan tuna di samudra Pasifik khususnya wilayah Indonesia dengan basis Perairan Sulawesi Utara telah berkembang sejak puluhan tahun silam. Beberapa jenis alat tangkap ikan yang banyak digunakan untuk menangkap tuna antara lain huhate (pole and line), pukat cincin (purse seine), jaring insang hanyut (drift gill net), rawai tuna (tuna long line) dan pancing tangan (hand line). Salah satu wilayah potensial penangkapan ikan tuna yakni wilayah Perairan Sangihe. Data instansi terkait menyatakan bahwa produksi perikanan laut di Kabupaten Kepulauan Sangihe yakni jenis tuna mata besar (Thunnus obesus) sebesar 18,30 ton; cakalang (Katsuwonus pelamis) 304,20 ton; madidihang (Thunnus albacores) 115,9 ton; albakora (Thunnus alalunga) 11,1 ton; tuna sirip biru selatan (Thunnus maccoyii) 2,00 ton. Jumlah armada tangkap kapal bermotor sebanyak 126 unit dan perahu bermotor sebanyak 716 unit yang mengoperasikan alat tangkap rawai tuna 249 unit; rawai hanyut lain 342 unit; huhate 4 unit; pancing tonda 4.820 unit (Anonymous, 2010).

Penangkapan ikan tuna terutama untuk jenis tuna madidihang, tuna mata besar dan cakalang antara lain dengan menggunakan alat tangkap pancing tuna (tuna handline) dengan alat bantu penangkapan rumpon ataupun ponton. Habibi, et al. (2011), menyatakan bahwa penangkapan dilakukan ketika ikan tuna berada di dekat permukaan air dengan mengikuti atau memotong jalur pergerakannya.

Sarana penangkapan yang digunakan dalam mengoperasikan pancing tangan ini yaitu perahu tipe lambut bermesin dalam (inboard) dan perahu katir tipe pumpboat. Tingkat eksploitasi ikan tuna di Sangihe dalam beberapa tahun ini meningkat tajam, seiring dengan adanya ekspansi 
pembelian bahan baku tuna segar dari industri perikanan yang berpangkalan di Kota Bitung, Sulawesi Utara. Ikan tuna tangkapan nelayan lokal dengan alat tangkap pancing tangan umumnya dibeli oleh pedagang pengumpul yang merupakan perpanjangan tangan dari industri perikanan. Penangkapan ikan tersebut dilakukan pada perairan lepas Sangihe di sekitar lokasi rumpon/ponton yang banyak tersebar di wilayah tersebut.

Peralatan navigasi untuk menemukan lokasi rumpon/ponton dengan menggunakan kompas dan Global Positioning System (GPS). Penggunaan GPS ini menjadi suatu hal mutlak bagi nelayan karena mempermudah tujuan ke daerah penangkapan ikan, sehingga mengurangi pemakaian bahan bakar dan waktu. Pemanfaatan teknologi ini di wilayah perairan Sangihe masih terhambat dikarenakan belum adanya kerjasama yang baik diantara pihak terkait dengan nelayan. Nelayan pada umumnya keberatan untuk memberitahukan daerah tangkapan ikan mereka sedangkan di sisi yang lain, pihak instansi terkait yang bertugas menginformasikan daerah tangkapan potensial sangat membutuhkan informasi ini sebagai kebenaran cek lapangan dari pemetaan daerah tangkapan yang telah dihasilkan. Karnan (2009), menyatakan apabila informasi kondisi sumberdaya pesisir di suatu kawasan dapat diperkirakan misalnya peta daerah tangkapan yang dihasilkan dilengkapi dengan data yang lengkap dari lapangan, maka formulasi pengelolaan sumberdaya ini secara berkelanjutan akan lebih mudah dilakukan.

Informasi ilmiah tentang daeraty penangkapan ikan tuna di Perairan Sangihe belum tersedia. Oleh karena itu, perlu untuk melakukan penelitian tentang pemetaan daerah penangkapan ikan tuna yang tertangkap dengan pancing tangan di wilayah Perairan Sangîhe. Benelitian ini bertujuan untuk memetakan daerah penangkapan ikan tuna dengan alat tangkap pancing di Perairan Sangihe dan mengidentifikasi jenis-jenis ikan tuna yang tertangkap berdasarkan posisi geografis daerah penangkapan ikan. Hasil penelitian ini diharapkan akan dapat memberikan informasi ilmiah yang bermanlaat tentang lokasi daerah penangkapan ikan tuna yang potensial dan sebagai salah satu bahan pertimbangan dalam penentuan kebijakan perikanan tangkap.

\section{METODE PENELITIAN}

Penelitian ini dilaksanakan di lokasi penangkapan ikan tuna dengan alat tangkap hand line, yaitu perairan Kendahe, perairan Pulau Lipang dan sekitarnya pada bulan Oktober-Desember 2012.
Penelitian ini menggunakan metode survei dan observasi langsung. Survei dilakukan untuk mengumpulkan data primer dan data sekunder (Singarimbun, 1989). Data primer diperoleh dengan cara mengikuti langsung operasional penangkapan ikan pada tiga jenis armada penangkap ikan. Pencatatan jumlah, jenis ikan hasil tangkapan dan posisi geografis dilakukan pada setiap armada alat tangkap pancing yang diikuti. Data sekunder berupa potensi perikanan, jumlah alat tangkap pancing tuna, harga ikan tuna dan upaya penapgkapan diperoleh dari berbagai instansi seperti pinas Kelautan dan Perikanan Kabupaten Kepulawán Sangihe, Badan Pusat Statistik, studifiteratur dan sebaran kuesioner.

Peralatan dan bahan pendukung pada penelitian ini yakni perahu tipe pelanglbermotor dan kapal bermotor untuk transportasi ke lokasi penangkapan ikan; alat tangkap pancing tangan yang dimiliki oleh nelayan Tokal untuk menangkap ikan tuna; GPS Garmín tipe E-trex untuk menentukan posisi geografis ldkasi penelitian; perangkat lunak Map Source, Arch View GIS 3.3 dan Google Earth untuk memetâkan daerah penangkapan ikan; peta laut No. 403 Kepulauan Sangihe.

\section{HASIL DAN PEMBAHASAN}

Alat tangkap pancing tuna oleh masyarakat nelayan Sangihe dikenal dengan nama lokal latage, sehingga operasional penangkapan ikan tuna ini sering dinamakan melatage. Peningkatan efektifitas dan produktivitas hasil tangkapan dilakukan dengan cara memodifikasi konstruksi. Modifikasi operasional penangkapan ikan dilakukan dengan cara menyuntikan ekstrak cumi-cumi (cisabu) pada umpan yaitu ikan layang (Decapterus sp.) sebagai media atraktor. Secara umum konstruksi pancing tuna terdiri dari penggulung tali pancing, tali utama, tali cabang, pemberat, kili-kili, mata kail dengan uraian sebagai berikut:

1. Tali utama, berfungsi untuk dapat mengikatkan pemberat dan tali cabang berbahan Polyamide monofilament (PA mono) no. 170, $435 \mathrm{~m}$.

2. Tali cabang, ada dua jenis tali yang dipakai, yang pertama berfungsi sebagai tempat untuk mengikatkan mata kail, sedangkan yang kedua untuk membuat cisabu pecah dari kantong plastik. Kedua tali cabang ini memiliki ukuran yang tidak sama. Nomor 150 untuk tali yang digunakan mengikat mata kail sedangkan yang satunya bernomor 40 .

3. Pemberat yang digunakan ada dua macam, yaitu timah sebagai pemberat pancing dan batu se- 
bagai pemberat sementara dan tempat untuk meletakkan potongan ikan umpan.

4. Kili-kili terdiri dari tiga bagian. Bagian pertama dan kedua letaknya pada pemberat yang berfungsi untuk menyambungkan tali dengan pemberat. Sedangkan bagian yang ketiga berfungsi untuk menyambungkan tali cabang ke tali utama.

5. Mata kail, berfungsi sebagai tempat mengaitkan umpan yang digunakan. Mata kail yang dipakai bernomor 12 (cicago) yang terbuat dari besi.

6. Penggulung tali pancing, berfungsi sebagai tempat menata tali pancing.

Desain grafis dan spesifikasi alat tangkap ini dapat dilihat pada Gambar 1 dan Tabel 1.

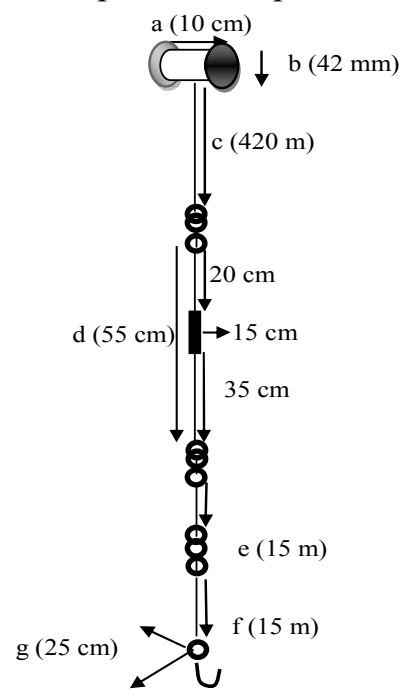
Keterangan :
a. Lebar penggulung tali pancing
b. Diameter penggulung tali pancing
c. Panjang tali utama ke kili-kili pemberat.
d. Panjang total pemberat
e. Panjang tali utama ke 2 dari kili-kili ke 2 (pemberat) ke kili- kili 3.
f. Panjang tali anak dari kili-kili ke 3 sampai mata kail
g. Panjang tali cabang ke 2 untuk menusuk cisabu

Gambar 1. Desain grafis alat tangkap pañềng tuna.

Figure 1. Design of tuna handline fishing gear.

Tabel 1. Spesifikasi alat tangkap pancing tuna.

Table 1. Specification of tuna handline fishing gear.

\begin{tabular}{|c|c|c|c|c|c|c|}
\hline 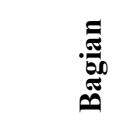 & 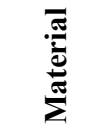 & . & 己气 & Q $\widehat{\overparen{E}}$ & 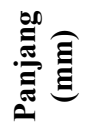 & $\sum$ \\
\hline $\begin{array}{l}\text { Penggulur } \\
\text { tali }\end{array}$ & & & - & 42 & 100 & 1 \\
\hline $\begin{array}{l}\text { Tali } \\
\text { utama }\end{array}$ & & dolphin & 170 & 3 & 43.500 & 1 \\
\hline $\begin{array}{l}\text { Tali } \\
\text { cabang }\end{array}$ & mono & & $\begin{array}{r}150 \\
40\end{array}$ & $\begin{array}{l}2 \\
1\end{array}$ & $\begin{array}{r}1.500 \\
250\end{array}$ & 2 \\
\hline Swivel, & FE & & - & 14 & 60 & 3 \\
\hline $\begin{array}{c}\text { Mata } \\
\text { kail }\end{array}$ & FE & cicago & 11 & 45 & 45 & 1 \\
\hline \multirow[t]{2}{*}{ Pemberat } & Timah & rtex & - & - & 150 & 1 \\
\hline & Batu & - & - & - & - & 1 \\
\hline
\end{tabular}

Sumber: data penelitian 2012 .

Armada penangkapan ikan yang digunakan oleh nelayan dalam pengoperasian alat tangkap ini dapat dikategorikan dalam 3 jenis armada berdasarkan bentuk dan tipe penggeraknya, yaitu:
1. Perahu katir bermesin dalam tipe pelang dengan daya pendorong 5 HP dengan tenaga kerja 12 orang. Dimensi utama panjang $8,5 \mathrm{~m}$, lebar $0,90 \mathrm{~m}$ dan tinggi $0,85 \mathrm{~m}$, dengan palka terbuka. Waktu tempuh rata-rata ke lokasi penangkapan ikan 2-3 jam.

2. Perahu katir bermesin dalam tipe pumpboat dengan daya pendorong 150 HP 6 silinder. Tenaga kerja sebanyak 5-6 orang. Dimensi utama panjang $11 \mathrm{~m}$, lebar $2,32 \mathrm{~m}$ dan tinggi $2,80 \mathrm{~m}$. Memiliki 2 buah palka yang berisi es. Waktu tempuh untuk sampai ke lokasi perangkapan ikan yaitu 2-3 jam.

3. Perahu/kapal bermesin dalam fipe lambut dengan daya pendorong Mitsubishi $150 \mathrm{HP}, 31 \mathrm{GT}$. Tenaga kerja $7-10$ orang. Dimensi utama panjang 22,5 m, lebar 2,60 m dan tinggi 2,80 m.

Selanjutnya, jenis danjumlah armada penangkap milik nelayap lokal yang mengusahakan alat tangkap pancing tuna di kawasan penelitian serta pangkalannya disajikan dalam Tabel 2 berikut ini.

Tabel 2. Jenis, jumlah dan pangkalan armada penangkap ikan.

Table 2. Type, amount and port base of fishing boat.

\begin{tabular}{rrl}
\hline Tipe & $\sum_{\text {(unit) }}$ & \multicolumn{1}{c}{ Pangkalan } \\
\hline perahu & Kendahe, Tahuna \\
Ldmbut & 2 & Kendahe, Tahuna \\
Yumpboat & 4 & Nusa Tabukan, Kendahe, Tabukan \\
Pelang & 22 & Kendahe, Tahuna, Nusa Taba \\
\hline
\end{tabular}

Sumber: data penelitian 2012.

Pengoperasian pancing tuna meliputi tahap persiapan, pencarian daerah penangkapan ikan, penurunan alat tangkap dan pengangkatan/penarikan alat tangkap. Tahap persiapan yang dilakukan terdiri dari persiapan perbekalan melaut, umpan, pemeriksaan peralatan, bahan bakar, es dan pemberat batu. Selain itu kondisi laut, arah angin dan posisi kapal merupakan hal mutlak yang harus diperhatikan dalam menuju daerah penangkapan ikan. Untuk armada yang telah memiliki alat bantu rumpon (Fish Aggregating Device/FAD), penjaga rumpon akan memberikan tanda apabila dapat melakukan operasi penangkapan ikan. Untuk armada penangkap yang tidak memiliki rumpon biasanya menambatkan perahunya pada rumpon/ponton dengan persetujuan penjaga rumpon tersebut terlebih dahulu.

Proses pemancingan dilakukan setelah penyediaan umpan. Umpan ikan layang akan dipotong menjadi dua bagian, bagian yang pertama dipotong-potong menjadi beberapa bagian, sedangkan bagian yang kedua tidak dipotong melainkan dikaitkan di mata kail bersama cisabu. Mata kail yang telah diberi umpan dilingkarkan pada batu bersama cisabu dengan tali cabang kedua dan juga 
potongan-potongan ikan yang lainnya. Selanjutnya para awak kapal akan menurunkan pancing tersebut hingga mencapai kedalaman tertentu $( \pm 80$ $100 \mathrm{~m}$ ). Menggerakkan tali pancing dengan cara disentak-sentak atau ditarik dan diturunkan secara berirama. Tali pancing ditarik agar supaya batu bisa terlepas dan cisabu bisa pecah berhamburan dari plastik. Pecahnya cisabu ini akan menarik perhatian ikan target untuk memakan umpan yang berhamburan tersebut. Penarikan tali pancing dilakukan sampai nelayan merasakan apabila sudah ada tarikan ikan yang memakan umpan tersebut maka tali pancing disentak dan secepatnya ditarik ke kapal. Penarikan pancing dilakukan hingga pemberat sudah berada di atas kapal, pemberat tersebut dipisahkan dari kumpulan tali agar memudahkan proses pemancingan selanjutnya. Setelah ikan muncul di permukaan dan dekat dengan kapal, maka pemancing lainnya memukul kepala ikan dan diangkat dengan menggunakan ganco. Ikan yang telah berhasil dinaikkan ke kapal, dibersihkan dengan air laut dan dimasukkan ke bak penampung (palka). Selanjutnya pancing tersebut diulurkan kembali ke laut untuk pengoperasian selanjutnya. Lama pengoperasian penangkapan tergantung pada banyaknya ikan yang akan memakan umpan dan kondisi laut pada saat pemancingan.

Rumpon dan ponton adalah salah satu jenis alat bantu penangkapan ikan yang dipasang di laut baik laut dangkal maupun laut dalam untuk mena rik gerombolan ikan agar berkumpul di sekitar alat ini, sehingga ikan mudah ditangkap. Ponton Berbeda dengan rumpon dalam hal konstruksi pada media pengapung yang terbuat daribesi berbentuk seperti torpedo. Daya tahan pontondi laut lebih lama dibandingkan dengan rumporn.

Dilihat dari kedalaman lokasi pemasangan rumpon/ponton milik Mnasyarakat nelayan Sangihe termasuk kategori laat dalam. Umumnya, status kepemilikannya dimitiki oleh pengusaha perikanan yang mengusakakan alat tangkap pukat cincin dan pancing tangan?

Jenis alat tangkap yang menggunakan rumpon untuk diadakan operasi penangkapan ikan adatah pukat cincin dan pancing tangan. Status kepemilikan ponton tersebut adalah dimiliki oleh pengusaha perikanan yang berpangkalan di Tahuna dan sebagian lainnya adalah milik nelayan Filipina. Penempatan rumpon dan ponton yang masuk di wilayah perairan Laut Sulawesi kadangkala memicu polemik diantara para nelayan lokal dan nelayan asing. Daerah penangkapan ikan tuna di Perairan Sangihe umumnya dilakukan pada bagian barat Perairan Sangihe. Hal ini bisa dimaklumi ka- rena pada sebagian besar wilayah tersebut banyak ditemukan rumpon dan ponton sebagai media pengumpul ikan dan juga penghadang ruaya ikan target. Intensitas penangkapan ikan terutama dilakukan pada saat musim ikan yaitu selang bulan Maret-November. Posisi geografis daerah penangkapan ikan tuna dengan menggunakan alat tangkap pancing tuna disajikan pada Tabel 3.

Tabel 3. Posisi geografis daerah penangkapan ikan Tuna.

$\frac{\text { Table 3. Geographic positions of tuna's FADs. }}{\text { Nama }}$

\begin{tabular}{|c|c|c|c|c|}
\hline \multirow[b]{2}{*}{ No } & \multirow{2}{*}{$\begin{array}{l}\text { Nama } \\
\text { rumpon/ } \\
\text { ponton }\end{array}$} & \multicolumn{2}{|c|}{ Posisi } & \\
\hline & & $\begin{array}{c}\text { Lintang } \\
\text { Utara }\end{array}$ & $\begin{array}{l}\text { Bujur } \\
\text { Timur }\end{array}$ & Ket. \\
\hline 1. & 126 & $3^{0} 57^{\prime}$ & $125^{8} 15^{\prime}$ & Ponton \\
\hline 2. & Marcopolo 03 & & $125 \%$ & Ponton \\
\hline 3. & Marcopolo 33 & & $125^{\circ} 18^{\prime}$ & Ponton \\
\hline 4. & Talawid & & $125^{\circ} 18^{\prime}$ & Rumpon \\
\hline 5. & Sri 08 & & $125^{\circ} 17^{\prime}$ & Rumpon \\
\hline 6. & Lipang & & $125^{\circ} 18^{\prime}$ & Ponton \\
\hline 7. & Kendahe & & $125^{\circ} 12^{\prime}$ & Ponton \\
\hline 8. & Malebur 1 & & $125^{\circ} 13^{\prime}$ & Rumpon \\
\hline 9. & Malebur 2 & $3^{0} 45^{\prime}$ & $125^{\circ} 12^{\prime}$ & Rumpon \\
\hline
\end{tabular}

Sumber: data penelitian, 2012.

Hastl tangkapan diperoleh yaitu dari perahu katiptipe pelang bermesin dalam (inboard) 5 PK adalah tuna jenis tuna sirip kuning/madidihang (Thunnus albacores) sebanyak 2 ekor dengan panjang cagak masing-masing 32 dan $34 \mathrm{~cm}$; dari armada penangkap perahu katir tipe pumpboat bermesin dalam (inboard) 150 PK sebanyak 502 ekor, yang terdiri dari 100 ekor cakalang (Katsuwonus pelamis), dan 402 ekor panitang. Cakalang yang tertangkap memiliki rata-rata panjang $16,5 \mathrm{~cm}$; dari perahu tipe lambut bermesin dalam (inboard) 150 PK sebanyak 104 ekor, yang terdiri dari 102 ekor madidihang; 2 ekor lainnya adalah tuna mata besar (Thunnus obesus). Pengukuran panjang tubuh ikan yang tertangkap (FL) yaitu madidihang yang tertangkap pada panjang 145-168 cm; Tuna mata besar yang tertangkap masing-masing memiliki panjang $181 \mathrm{~cm}$ dan $180 \mathrm{~cm}$. Penguluran mata pancing pada kedalaman $240 \mathrm{~m}$ tertangkap madidihang sebanyak 54 ekor; kedalaman 150 m tertangkap 1 ekor; kedalaman 255 m tertangkap 3 ekor; tuna tertangkap sebanyak 1 ekor pada kedalaman $180 \mathrm{~m}$ dan tertangkap 1 ekor lainnya pada kedalaman $200 \mathrm{~m}$.

Hasil tangkapan tersebut dianalisa berdasarkan sebaran alat bantu penangkapan ikan yang disajikan pada Tabel 4. Secara umum wilayah penangkapan ikan tuna terkonsentrasi pada bagian barat Perairan Sangihe, hal tersebut dapat dilihat dengan banyaknya rumpon/ponton pada daerah tersebut. Banyaknya alat bantu ini pada kawasan tersebut amat dimungkinkan karena berdasarkan pe- 
nuturan pemilik usaha penangkapan ikan bahwa kawasan tersebut merupakan alur migrasi ikan tuna yang telah dikenal cukup lama, selain itu keadaan topografi perairan yang amat dalam dan curam.

Tabel 4. Sebaran hasil tangkapan pancing tuna pada FAD.

Table 4. Distribution of tuna catches by FADs.

\begin{tabular}{cllr}
\hline No & $\begin{array}{c}\text { Nama rumpon/ } \\
\text { ponton }\end{array}$ & $\begin{array}{c}\text { Hasil tangkapan } \\
\text { ikan }\end{array}$ & $\begin{array}{c}\text { Jumlah } \\
\text { (ekor) }\end{array}$ \\
\hline 1. & 126 & Madidihang & 20 \\
2. & Marcopolo 03 & Madidihang & 43 \\
3. & Marcopolo 33 & Madidihang & 7 \\
4. & Talawid & Madidihang & 9 \\
5. & Sri 08 & Madidihang & 20 \\
& & Tuna mata besar & 1 \\
6. & Lipang & Cakalang & 34 \\
7. & Kendahe & Cakalang & 44 \\
8. & Malebur 1 & Cakalang & 23 \\
9. & Malebur 2 & Cakalang & 12 \\
\hline Sumber: data penelitian, 2012.
\end{tabular}

Sumber: data penelitian, 2012

Arifin (2008), melaporkan bahwa tuna merupakan jenis ikan yang masuk dalam kelompok ruaya ikan yang muncul sedikit di atas lapisan termoklin pada siang hari dan akan beruaya ke lapisan permukaan pada sore hari. Sedangkan pada malam hari akan menyebar diantara lapisan permukaan dan termoklin. Fenomena tersebut diterapkan oleh nelayan dengan mengoperasikan alat tangkap pada siang hingga menjelang sore hari. Aktivitas waktu penangkapan ikan paling banyak dilakukan pada waktu tersebut, terutama pada alat bantu yang tidak memiliki alat penerang.

Wilayah penangkapan ikan pada posisi geografis $3^{\circ} 47^{\prime} \mathrm{LU}-125^{\circ} 19^{\prime} \mathrm{BT}$ (ponton marcopolo 03) memberikan hasil tangkapan yaufg (ebih tinggi bila dibandingkan dengan wilayaht tangkapan yang lain terutama untuk hasil tangkapan madidihang. Gambaran tersebut menandakan bahwa efektifitas penangkapan ikan jenis tersebut pada wilayah tersebut sangat tinggi. Hal ini bisa terjadi karena bila dibandingkan dengan lokasi yang lain, jumlah armada yang bertambat pada lokasi tersebut mencapai 7-8 armada, selain karena faktor dekat dengan pangkalanjuga karena lebih mudah ditemui ketika berangkat dari pangkalan wilayah Kendahe.

Wilayah penangkapan ikan pada posisi geogrdfis $3^{\circ} 40^{\prime} \mathrm{LU}-125^{\circ} 12^{\prime} \mathrm{BT}$ (ponton kendahe) yang banyak digunakan oleh nelayan Nusa Tabukan memberikan hasil tangkapan yang tinggi untuk komoditi cakalang. Ponton tersebut ditambatkan oleh 2-3 armada penangkapan ikan sehingga tingkat penggunaan ponton tersebut kurang bila dibandingkan daerah lain yang hasil tangkapan utamanya jenis cakalang.

Salah satu faktor yang mempengaruhi banyaknya hasil tangkapan yang didapat pada rum- pon/ponton yaitu adalah jumlah perahu/armada penangkap ikan yang menambatkan armadanya pada alat bantu tersebut. Jumlah armada yang beroperasi di rumpon/ponton tersebut yaitu 7-8 armada, jumlah tersebut relatif banyak bila dibandingkan di rumpon/ponton yang lain yang hanya berkisar 3-4 armada. Tidak adanya batasan jelas jumlah armada tangkap yang boleh tambat pada setiap alat bantu penangkapan ikan, turut memicu intensitas penangkapan yang tinggi pada daerah tersebut.

Beberapa faktor pembatas yang unum ditemui dalam pengoperasian alat tangkap paneíng tuna dengan menggunakan media rumpon/ponton untuk nelayan kecil yang menggunakan perahu tipe pelang yaitu waktu melaut yang singkat (one day fishing) karena keterbatasah sarana penunjang yang ada di atas armada.

Perairan Kendahe dan Perairan Lipang merupakan daerah potensial untuk penangkapan ikan tuna, cakalang dan sebagainya. Perairan tersebut banyak dijumpai fumpon dan ponton milik nelayan Sangihe dan miliknelayan Philiphina. Banyaknya alat bantu penangkapan ikan tersebut secara tidak langsung berdampak pada banyaknya armada penangkap ikan dikawasan tersebut. Sebagai wilayah potensjal penangkapan ikan, keberadaan alat bantu penangkapan ikan tersebut membuat intensitas penangkapan ikan di kawasan tersebut menjadi tinggi.

Dari komposisi target spesies dan ukuran panjang tubuh ikan, maka alat tangkap pancing tuna memenuhi kriteria keramahan alat tangkap, dimana yang tertangkap adalah ikan-ikan yang berukuran besar dan setidaknya pernah memijah. Panjang cagak ikan yang tertangkap yang paling besar untuk jenis madidihang yaitu $75 \mathrm{~cm}$ dan terkecil yaitu $63 \mathrm{~cm}$. Panjang cagak tuna mata besar yang tertangkap yaitu $78 \mathrm{~cm}$. Ukuran panjang cagak yang paling besar tertangkap untuk jenis cakalang yaitu $65 \mathrm{~cm}$ dan yang terkecil yaitu $38 \mathrm{~cm}$.

Ketahanan mutu kesegaran ikan dari setiap armada penangkapan ikan juga turut memberikan andil terhadap kualitas hasil tangkapan. Hal ini sejalan dengan yang dikatakan oleh Mahyuddin (2012), bahwa produktivitas para nelayan Indonesia hingga saat ini masih tergolong rendah, hal ini disebabkan oleh penggunaan armada perikanan yang secara nasional masih didominasi oleh kapal berukuran kecil, yaitu perahu tanpa motor, perahu motor tempel dan kapal ikan berukuran 0,5-3 gross tonnage (GT). Kelemahan dari penggunakan armada kecil antara lain para nelayan memiliki hari layar yang singkat (one day fishing), daya tampung ikan hasil tangkapan yang kecil, kualitas ikan yang 
kurang terjaga atau tingginya tingkat kehilangan mutu (losses), yang berakibat pada daya jual yang rendah, sementara biaya produksi terus meningkat.

Menurut Atapattu (1991) yang diacu $d a-$ lam Satria (2010), menyatakan bahwa penggunaan rumpon sebagai alat bantu penangkapan mempunyai tujuan utama untuk meningkatkan laju tangkap dengan pengurangan biaya produksi, mengurangi waktu untuk mencari gerombolan ikan sehingga mengurangi biaya operasi kapal, meningkatkan efisiensi penangkapan serta memudahkan operasi penangkapan ikan yang berkumpul di sekitar rumpon. Jenis ikan yang tertangkap oleh pukat cincin pada free schooling ternyata berukuran lebih besar dibanding ikan yang ditangkap di sekitar rumpon (Itano et al. 2006). Selanjutnya ikan tuna yang berukuran kecil umumnya berasosiasi dengan ikan cakalang yang senang tinggal dekat rumpon (Matsumoto, et al. 2006; Wudianto dan Kusno, 2008). Namun demikian, tidak semua ikan tuna yang tertangkap di sekitar rumpon berukuran kecil, hal ini sangat tergantung pada jenis alat tangkap yang digunakan. Alat tangkap pancing ulur (hand line) menangkap ikan tuna berukuran lebih besar jika dibanding ikan tuna yang tertangkap oleh pukat cincin (Babaran, 2006). Pancing ulur dioperasikan di perairan yang lebih dalam dimana lapisan renang ikan tuna besar terdapat di lapisan tersebut (Wudianto, 2010). Nakamura (1969) dalam Baskoro, et al. (2011) menyatakan bahwa hampir semua jenis tuna, umumnya membentuk kelompok campuran dua atau tiga jenis tuna. Kelompok-kelompok campuran tersebut umumnya terdiri dari spesies-spesies yang ukurannya sama. Cakalang lebih mudah ditangkap dengan jenis alat tangkap pukat cincin ketika kelompok cakalang tersebut bersama-sama dengan jenis tuna lainnya seperti madidihang.

Jenis ikan yang tertangkap pada rumpon/ ponton dari segijentis juga bervariasi terutama untuk jenis tuná sirip kuning dan cakalang. Variasi jenis ikan îni armat dimungkinkan karena adanya perbedaan suthu dari masing-masing jenis ikan tersebut Cakalang umumnya tertangkap pada hampir semua rumpon/ponton dengan jumlah yang bervariasi, karena sifat cakalang yang suka bergerombol atau membentuk schooling. Nelayan tuna handline menempatkan rumpon dan ponton pada kelompok prioritas daerah penangkapan ikan, selain faktor adanya kepastian ikan yang menjadi target juga dengan menangkap ikan di rumpon dan ponton mereka dapat menghemat pemakaian bahan bakar minyak. Penangkapan ikan disekitar rumpon dan ponton ternyata lebih efektif bila dibandingkan dengan usaha nelayan mencari gerombolan ikan. Dari segi produksi yang dihasilkan oleh nelayan, produktifitas hasil tangkapan nelayan yang menambatkan perahu mereka di rumpon dan ponton lebih produktif jika dibandingkan dengan mereka mencari gerombolan ikan di laut bebas.

\section{KESIMPULAN}

kesimpulan :

Dari hasil penelitian ini-dapat ditarik

Wilayah penangkapan ikan tuna menggunakan pancing dapat dipetakan dengan melihat hasil tangkapan pada masing-masing alat bantu penangkapan ikan. Jumlah alat bantu penangkapan ikan yang terkonsentrasi pada satu kawasan penangkapan memberikan pengaruh pada hasil tangkapan.

\section{DAFTAR PUSTAKA}

A (

Babaran RP. 2006. Payao fishing and its impact to tuna stocks: a preliminary analisys. Second regular scientific meeting. WCPFC. Manila 7-8 August 2006. FT WP-7. $12 \mathrm{p}$.

Baskoro M dan Taurusman AAm. 2011. Tingkah laku ikan: Hubungannya dengan ilmu dan teknologi perikanan tangkap. Lubuk Agung. Bandung. 258 hal.

Habibi A, Ariyogagautama, Sugiyanta. 2011. Perikanan tuna: panduan penangkapan dan penanganan. 32 hal.

Karnan. 2009. Penggunaan penginderaan jarak jauh dan sistem informasi geografis dalam pengelolaan perikanan tangkap skala kecil berkelanjutan. Jurnal Biologi Tropis. Vol.10 No 1, Januari 2009. p: 17-23. ISSN 1411-9587.

Mahyuddin B. 2012. Kebutuhan teknologi untuk penangkapan ikan. Makalah seminar nasional kelautan VIII Universitas Hang Tuah. Surabaya. 16 hal.

Satria H. 2010. Distribusi, kelimpahan dan jenis-jenis plankton di lokasi sekitar rumpon dasar pantai utara Pekalongan. Seminar nasional biologi. Fakultas Biologi UGM, Yogyakarta. Hal 291-312.

Singarimbun ES.1989. Metode penelitian survei. LP3ES, Jakarta. 336 hal. 